Bond University

Research Repository

\title{
Profiling the sport of stand-up paddle boarding
}

Schram, Ben; Hing, Wayne; Climstein, Mike

Published in:

Journal of Sports Sciences

DOI:

10.1080/02640414.2015.1079331

Licence:

Unspecified

Link to output in Bond University research repository.

Recommended citation(APA):

Schram, B., Hing, W., \& Climstein, M. (2016). Profiling the sport of stand-up paddle boarding. Journal of Sports Sciences, 34(10), 937-944. https://doi.org/10.1080/02640414.2015.1079331

\footnotetext{
General rights

Copyright and moral rights for the publications made accessible in the public portal are retained by the authors and/or other copyright owners and it is a condition of accessing publications that users recognise and abide by the legal requirements associated with these rights.
}

For more information, or if you believe that this document breaches copyright, please contact the Bond University research repository coordinator. 
Title: Profiling the Sport of Stand Up Paddle Boarding

Running Title: Profiling Stand Up Paddle Boarding 


\section{Abstract}

2 Stand up paddle boarding (SUP) is a rapidly growing activity where only anecdotal evidence

3 exists for its proposed health and fitness benefits. The purpose of this study was to profile elite

4 and recreational SUP with respect to anthropometric, physiological and musculoskeletal

5 measurements. A total of 30 SUP participants (15 recreational, 15 elite) and 15 sedentary

6 controls participated in this study. Elite and recreational (rec) SUP participants had significantly

7 lower body fat than sedentary (sed) individuals, elite had significantly higher HDL and

8 significantly lower triglycerides than other groups during lipid profiling $(P>0.05)$. There were

9 significant differences $(P>0.05)$ between all groups in maximal oxygen uptake (elite $43.7, s=$

$105.89 \mathrm{ml} / \mathrm{kg} / \mathrm{min}$ vs rec $31.9, \mathrm{~s}=7.7 \mathrm{ml} / \mathrm{kg} / \mathrm{min}$ vs sed $20.4, \mathrm{~s}=3.7 \mathrm{ml} / \mathrm{kg} / \mathrm{min}$ ) and anaerobic

11 power outputs $(35.7, s=11.1 \mathrm{~W}$ vs $25.0, s=11.7 \mathrm{~W}$ vs $13.5, s=7.1 \mathrm{~W})$. The elite group

12 displayed significantly longer endurance than the recreational and sedentary group in the prone

13 bridge (elite 253.4, $s=67.6 \mathrm{sec}$ vs rec $165.6, s=42.2 \mathrm{sec}$ vs sed $69.7, s=31.2 \mathrm{sec}$ ) right sided

14 bridge (elite 107.9, $s=34.0 \mathrm{sec}$ vs recreational $68.2, s=24.1 \mathrm{sec}$ vs sed $34.6, s=15.5 \mathrm{sec}$ ) left

15 sided bridge (elite 99.8, $s=24.9 \mathrm{sec}$ vs rec $68.2, s=27.2 \mathrm{sec}$ vs sed $32.5, s=15.2 \mathrm{sec}$ ) and Biering

16 Sorensen test (elite $148.8, s=35.4 \mathrm{sec}$ vs rec $127.2, s=43.2 \mathrm{sec}$ vs sed $71.1, s=32.9 \mathrm{sec}$ ). Elite

17 SUP had significantly better static and dynamic postural control when compared to the other

18 groups. This study demonstrates the anthropometric, physiological and musculoskeletal values

19 representative of elite and recreational SUP. SUP appears to be associated with increased levels

20 of aerobic and anaerobic fitness, increased static and dynamic balance and a high level of

21 isometric trunk endurance.

22

23 Key words: profiling, water sports, aquatic, paddle boarding 


\section{Introduction}

27 Stand up paddle boarding (SUP) is a new sport and recreational activity, which is increasing in

28 popularity around the world due to its proposed health and fitness benefits and enjoyment

29 (Hammer, 2011). SUP is a hybrid of surfing and paddling in which participants can either

30 distance paddle and/or surf waves (Walker, Nichols, \& Forman, 2010). Many websites

31 anecdotally advocate the use of SUP to increase strength, fitness, core stability, balance and

32 decrease back pain. However, our recent review of the literature found no scientific evidence to

33 substantiate the proposed benefits.

34

35 Stand up paddle boarding is an activity in which the participant maintains a standing position on

36 a board similar to a surfboard. However, SUP boards are longer in length ( 8-15ft, 2.4-4.6m),

37 thicker (4-8in, $10-20 \mathrm{~cm})$ and wider $(26-31 \mathrm{in}, 66-78 \mathrm{~cm})$ than traditional surfboards. The SUP

38 participant propels the board across the surface of the water by the use of a long, single-bladed

39 paddle. While the standing position is unstable initially, it is continuously disturbed by the

40 motion of the board and the movement of the arms whilst paddling, providing a constant postural

41 challenge.

43 Stand up paddle boarding is low impact, making it suitable for all ages. Participants can utilize

44 almost any body of water to either paddle distances or surf waves and it is therefore an ideal

45 aquatic activity. Advantages to SUP include that it is performed whilst standing and that the

46 participant paddles bilaterally, alternating sides when required. It is a dynamic activity primarily

47 utilising the upper limbs with an isometric trunk muscle component.

49 As SUP can be performed in a competitive environment, it is assumed that participants would

50 require both aerobic and anaerobic fitness to be successful in distance competition. With a 
51 number of competitive SUP endurance events lasting in excess of five hours (Molokai2Oahu), a

52 high level of aerobic fitness appears to be required from its elite participants. Anaerobic fitness

53 is essential for short speed bursts and to catch waves.

54

55 A high level of dynamic balance and trunk muscle endurance is required by its participants and

56 are both considered important attributes of a SUP participant. Research has shown that dynamic

57 exercise with isometric contraction of the core muscles can increase the strength of core muscles

58 (Danneels, Vanderstraeten, \& Cambier, 2001) and that improved core stability occurs when

59 training on unstable surfaces (Behm, Leonard, Young, Bonsey, \& Mackinnon, 2005). Core

60 stability training is commonly integrated in later stages of rehabilitation programs due to higher

61 demands on the motor control system and increased electromyographic (EMG) recordings from

62 the abdominal musculature (Vera-Garcia, Grenier, \& McGill, 2000).

63

64 The importance of trunk muscle capability is twofold. Multidirectional stability is required in

65 athletic performance to optimise performance and minimize the risk of injury while endurance of

66 the muscles is required to support the passive structures of the spine (McGill, Grenier, Kavcic, \&

67 Cholewicki, 2003). It has therefore been suggested that trunk muscle assessment also be

68 multidirectional to ensure that stability in all planes is confirmed (Evans, Refshauge, \& Adams,

69 2007). It is assumed therefore that SUP participants would have both increased postural control

70 and high levels of isometric trunk endurance due to the training effect of the activity.

72 The rationale for comparison of elite and recreational SUP participants is to identify the

73 physiological and musculoskeletal attributes which differentiate the two groups. An indication of

74 the fitness attributes of elite SUP participants provides a guideline for an individual wanting to

75 succeed in competitive SUP. The profiling of SUP participants has yet to be quantified, leaving a 
76 gap in the scientific literature. Therefore, the purpose of this study was to provide original data

77 regarding the physiological and musculoskeletal profiles of SUP athletes and compare it to

78 sedentary individuals with no previous exposure to the activity.

79

80 Methods

81 This research utilized a cross-sectional observational study design. This study was approved by

82 the University Human Research Ethics committee (RO-1550) and each participant formally

83 consented to taking part in the study prior to any tests being performed. The physiological

84 profile measures included aerobic and anaerobic capacity, blood lipid profile (total cholesterol,

85 high density lipoprotein, low density lipoprotein and triglycerides) and body composition. A

86 musculoskeletal profile included static and dynamic balance assessment and isometric trunk

87 muscle endurance.

88

89 A total of 15 elite competitive (10 males \& 5 females) SUP participants and 15 recreational SUP

90 participants (10 males, 5 females) were recruited from the Stand Up Paddle Surfers Association

91 (Gold Coast, QLD, Australia). Elite participants were currently actively competing and ranked in

92 the national competition. Participants were without a history of back pain and were free from

93 any physical and psychological impairment. The recreational paddlers were required to have a

94 minimum of 1year experience in SUP and absolutely no competitive experience in SUP events.

95 The sedentary control group were to have never had any experience on a SUP and have been not

96 participating in any exercise in the last six months.

97

98 Participants attended the human performance laboratory where they were assessed for stature (to

99 the nearest $0.1 \mathrm{~cm}$ ) and mass (to the nearest $0.1 \mathrm{~kg}$ ) on a standard medical balance scale (Seca,

100700 , Hamburg, Deutschland). Body composition and basal metabolic rate was assessed using

101 bio-electrical impedance (BIA), Tanita Body Composition Analyzer MC-980MA, Illinois, USA) 
102 as this has been shown to successfully determine body composition (Lukaski, Bolonchuk, Hall,

103 \& Siders, 1986). Participants were advised to be rested from exercise for a minimum of $24 \mathrm{hrs,}$

104 be euhydrated and bladder and bowels emptied prior to the BIA assessment. Bloods lipids were

105 analysed prior to exercise using a portable analyser (Cardiochek, P.A. Indiana, USA) to ascertain

106 total cholesterol (TC), high density lipoproteins (HDL), low density lipoproteins (LDL) and

107 triglycerides (Trigs).

108

109 A continuous graded exercise test using a specialised SUP ergometer (KayakPro SUPErgo,

110 Miami, FL, USA) was used to determine maximal aerobic power (relative and absolute).

111 Maximal aerobic power $\left(\mathrm{VO}_{2 \max }\right)$ was determined using an automated expired gas analysis

112 system (Parvomedics TrueOne 2400 metabolic system, East Sandy, Utah, USA) which was

113 calibrated prior to each test. The expired gas analysis system meets Australian Institute of Sport

114 accreditation standards for precision and accuracy. The gas analysis software was configured to

115 breath by breath for collection however $\mathrm{VO}_{2}$ max was determined from the average of 30

116 seconds of max data collected.

117

118 The SUP ergometer $\mathrm{VO}_{2}$ max protocol involved participants familiarising themselves with the

119 equipment with a 2 minute warm up at their chosen intensity. The test then stared at an initial

120 power output of $5 \mathrm{~W}$ with a $5 \mathrm{~W}$ increase each minute until volitional exhaustion. Participants

121 were instructed to paddle as per normal, free to alternate paddling on each side ad libitum. Peak

122 exercise blood lactate levels were determined using a portable lactate monitor (Arkay Lactate

123 Pro Blood Lactate Monitor, Kyoto, Japan) and assessed at peak exercise, 1, 5 and 10 minutes

124 post exercise obtained from the finger. The highest blood lactate level measured was deemed the

125 peak lactate. Participant heart rates were monitored throughout the VO2max test with a 12 lead

126 ECG via telemetry (Mortara X-Scribe, WI, USA). 
128 On the subsequent visit to the laboratory, maximal anaerobic power was determined using the 129 same SUP ergometer (KayakPro SUPErgo, USA). Participants were allowed to choose their

130 preferred paddling side on the ergometer to ensure that an indication of their maximal power

131 output could be reached. Participants then paddled maximally for 10 seconds from a stationary

132 start. The maximal power was then determined using specialised software incorporated into the

133 SUP ergometer (eMonitor Pro 2 KayakPro, New Rochelle, NY, USA) which is interfaced with a

134 computer. Other anaerobic power parameters measured included distance covered in 10 seconds

135 and peak speed. A minimum of two days and a maximum of three days were allowed between

136 testing maximal aerobic and anaerobic power.

137

138 Static and dynamic postural control was assessed via a portable force platform (Kistler 2812D

139 with Bioware 4.0, $100 \mathrm{~Hz}$ sampling rate) with three piezoelectric force sensors used to calculate

140 the centre of pressure (COP) foot positions. The protocol was similar to methods used previously

141 by Palliard and colleagues (Palliard, Margnes, Portet, \& Breucq, 2011) in which six postural

142 conditions were tested. Static posture was tested for 50 seconds and dynamic posture was tested

143 on a seesaw for 25 seconds. These conditions were tested with eyes open (EO) and then repeated

144 with eyes closed (EC). The testing order was from most stable to least stable.

145

146 Center of Pressure (COP) signals were smoothed using a Butterworth filter with a $10 \mathrm{~Hz}$ low pass

147 cut off frequency. The $100 \%$ square (a square in which all the samples lie) was calculated post

148 collection via the range of both the $\mathrm{x}$ and $\mathrm{y}$ deviations. The COP sway path length (the total

149 distance travelled by the COP over the course of the trial duration) was calculated via the

150 distance between each sampling point. From the COP excursion, the COP velocity was

151 calculated (velocity=distance/time). 
153 Trunk muscle endurance was measured as per methodologies previously described by McGill

154 (McGill, Belore, Crosby, \& Russell, 2010). The endurance of the flexors of the spine was

155 assessed with a prone bridge, lateral flexors with a side bridge and the extensors with a Biering

156 Sorensen. The tests were terminated when the participant could no longer maintain the required

157 position as determined by the tester and that time was recorded.

160 Statistical Analysis

161 A one-way analysis of variance was used to compare differences between the groups. Post hoc

162 Tukey analysis was utilised to assess differences between the groups. Alpha was set at $P<0.05 a$

163 priori. All statistical analyses were completed using the IBM Statistical Package for the Social

164 Sciences (SPSS, Version 20.0) software program.

\section{Results}

167 All three groups $(n=45)$ were equally composed of 10 males and 5 females. Of the elite competitors, six were rated amongst the top ten in the world while other competitors were currently competing in the national competition of SUP in Australia. As seen in Table 1, there were no significant differences between the groups with regards to age, stature or mass. Elite SUP participants were on average, younger than both the recreational $(-4.9 \%)$ and sedentary 172 groups (-13.8\%). The sedentary group possessed the smallest stature with recreational SUP 173 being the tallest compared to both the sedentary $(+1.3 \%)$ and the elite group $(+0.5 \%)$. The elite 174 group was also the lightest with less total mass than both the recreational $(-0.4 \%)$ and sedentary 175 groups (-13.3\%). Both elite and recreational groups had significantly lower BMI $\left(\mathrm{F}_{2,42}=5.367\right.$, $\left.176 P=0.008, \eta^{2}=0.204\right)$ than the sedentary group $\left(-14.6 \%,-3.68 \mathrm{~kg} / \mathrm{m}^{2}, 95 \% \mathrm{CI}[-6.94,-0.42]\right.$, $177 P<0.01, d=0.42$ and $-15.7 \%,-3.92 \mathrm{~kg} / \mathrm{m}^{2}, 95 \%$ CI $[-7.18,-0.66], P>0.05, d=0.43$ respectively). 178 There were significant differences in body fat $\left(\mathrm{F}_{2,42}=13.098, P=0.001, \eta^{2}=0.384\right)$ with the elite 
179 group the leanest with $31.2 \%$ (relative) less fat than the recreational group and $77.4 \%$ (relative)

180 significantly less than the sedentary group (7.14\% body fat, 95\% CI [-17.68, -6.25$], P<0.001$,

$181 d=0.69)$. There were significant differences between the elite and recreational group when

182 compared to the sedentary group with respect to BMI and percentage body fat $(P<0.05)$.

183

184 Table 1: Participant demographics $(m e a n \pm S D) *=$ significant difference from sedentary $(P<0.05)$.

\begin{tabular}{lccc} 
& Elite $(\mathrm{n}=15)$ & Recreational $(\mathrm{n}=15)$ & Sedentary $(\mathrm{n}=15)$ \\
\hline Age (years) & $38.2 \pm 9.37$ & $40.07 \pm 7.44$ & $43.47 \pm 12.59$ \\
Height $(\mathrm{cm})$ & $174.3 \pm 8.0$ & $175.1 \pm 11.3$ & $173.2 \pm 9.9$ \\
Mass $(\mathrm{kg})$ & $76.5 \pm 10.6$ & $76.8 \pm 13.1$ & $86.7 \pm 17.3$ \\
BMI $\left(\mathrm{kg} / \mathrm{m}^{2}\right)$ & $25.18 \pm 2.56^{*}$ & $24.94 \pm 2.84^{*}$ & $28.86 \pm 5.09$ \\
Body fat $(\%)$ & $15.45 \pm 6.76^{*}$ & $20.27 \pm 6.86^{*}$ & $27.41 \pm 5.64$ \\
\hline
\end{tabular}

185

186 Blood lipid profiling demonstrated no significant differences between groups in total cholesterol, 187 although elites had lower TC than both the recreational $(+15.2 \%)$ and the sedentary $(+15.2 \%)$, 188 which is indicative of lower cardiovascular risk. The elite SUP had a significantly $\left(\mathrm{F}_{2,42}=7.407\right.$, $\left.P=0.002, \eta^{2}=0.26\right)$ higher HDL as compared to both recreational $(+28 \%)$ and sedentary controls $(+57.9 \%)$. Elite SUP also demonstrated a significantly $\left(\mathrm{F}_{2,42}=5.396, P=0.008, \eta^{2}=\right.$ $0.20)$ lower LDL as compared to both recreational (-25.1\%) and controls (-58.2\%). The elite group displayed significantly lower triglyceride $\left(F_{2,42}=6.483, P=0.004, \eta^{2}=0.24\right)$ levels than the recreational group $(P<0.05)$ and the control group $(P<0.01)$. There were no significant differences between the recreational and sedentary groups with respect to triglycerides (Table 2). 


\begin{tabular}{lccc} 
& Elite $(\mathrm{n}=15)$ & Recreational $(\mathrm{n}=15)$ & Sedentary $(\mathrm{n}=15)$ \\
\hline Total cholesterol $(\mathrm{mmol} / \mathrm{L})$ & $4.02 \pm 0.79$ & $4.63 \pm 1.11$ & $4.63 \pm 0.67$ \\
HDL $(\mathrm{mmol} / \mathrm{L})$ & $2.10 \pm 0.47^{*}$ & $1.64 \pm 0.61$ & $1.33 \pm 0.55$ \\
Triglycerides $(\mathrm{mmol} / \mathrm{L})$ & $0.82 \pm 0.19^{*} \dagger$ & $1.37 \pm 0.68$ & $1.40 \pm 0.49$ \\
LDL $(\mathrm{mmo} / \mathrm{L})$ & $1.70 \pm 0.85^{*}$ & $2.27 \pm 0.93$ & $2.69 \pm 0.67$ \\
\end{tabular}

198

199

200 With regard to maximal aerobic power, the $\mathrm{VO}_{2 \max }$ of the elite group was significantly higher

$\left.201 \mathrm{~F}_{2,42}=83.53, P=0.000, \eta^{2}=0.73\right)$ in both relative $(+37.1 \%,+11.83 \mathrm{ml} / \mathrm{kg} / \mathrm{min}, 95 \% \mathrm{CI}[6.53$,

$20217.13], P<0.001, d=0.65)$ and absolute terms $\left(F_{2,42}=24.71, P=0.000, \eta^{2}=0.79\right)(+51.3 \%$,

$203+2.23 \mathrm{~L} / \mathrm{min}, 95 \% \mathrm{CI}[1.79,2.66], P<0.05, d=0.58)$ as compared to the recreational group and

204 the sedentary group $(+114.9 \%,+23.37 \mathrm{ml} / \mathrm{kg} / \mathrm{min}, 95 \%$ CI $[18.07,28.67],+85.2 \%,+1.56 \mathrm{~L} / \mathrm{min}$,

$20595 \%$ CI $[1.12,1.99]$ respectively) (Table 3$)$. There was also a significant difference $(P<0.01)$

206 between the recreational and sedentary groups with these two parameters $\left(\mathrm{VO}_{2}\right.$ max relative,

$207+56.8 \%,+11.55 \mathrm{ml} / \mathrm{kg} / \mathrm{min}, 95 \% \mathrm{CI}[6.24,16.85] \mathrm{VO}_{2} \max$ absolute, $+33.3 \%,+0.67 \mathrm{~L} / \mathrm{min}, 95 \%$

208 CI $[0.23,1.11])$. With regard to gender differences, elite males recorded a mean $46.8, s=3.7$

$209 \mathrm{ml} / \mathrm{kg} / \mathrm{min}$ and elite female's $37.5, s=4.2 \mathrm{ml} / \mathrm{kg} / \mathrm{min}$. Recreational participants were lower with

210 a mean score for the males $35.3, s=6.6 \mathrm{ml} / \mathrm{kg} / \mathrm{min}$ and recreational females $25.2, s=4.9$

$211 \mathrm{ml} / \mathrm{kg} / \mathrm{min}$ while the sedentary males achieved a mean VO2max of $21.9, \mathrm{~s}=3.1 \mathrm{ml} / \mathrm{kg} / \mathrm{min}$ and

212 females $17.4, \mathrm{~s}=3.0 \mathrm{ml} / \mathrm{kg} / \mathrm{min}$.

213

214 There were no significant differences between groups in regards to respiratory exchange ratio,

215 peak heart rate or peak lactate. The elite group reached $102.7 \%$ of their age predicted maximum

216 heart rate (220-age), whilst recreational participant's attained $103.9 \%$ and sedentary participants

$21798.0 \%$ of their age predicted maximum heart rate. The peak aerobic power achieved was 
218 significantly higher in the elite group $(30.5, s=6.0 \mathrm{~W})$ as compared to the recreational group $219(P<0.01,+43.7 \%)$ and the sedentary group $(P<0.01,+188.8 \%)$ and also when comparing the 220 recreational to sedentary groups $(P<0.01,+101.0 \%)$. A significantly greater peak stroke rate

$221(P<0.01,+25.5 \%)$, distance covered during the test $(P<0.01,+48.5 \%)$ and peak aerobic speed $222(P<0.01,+13.0 \%)$ was recorded from the elite group when compared to the recreational group 223 and the sedentary group $(P<0.01,+64.7 \% ; P<0.01,102.7 \% ; P<0.01,+45.3)$. Significant

224 differences were also observed in peak stroke rate $(P<0.01,+31.2 \%)$, distance covered $(P<0.05$,

$225+36.5 \%)$ and peak speed achieved during the test $(P<0.01,+28.7 \%)$ between the recreational and 226 sedentary groups.

227

228 The anaerobic test displayed significant differences between all of the groups in all measurements (Table 3). The peak power output of the elite group was significantly higher than the recreational group $\left(P<0.05,+42.5 \%,+10.63 \mathrm{~W}, 95 \% \mathrm{CI}[1.62,19.63], \eta^{2}=0.461\right)$ and the sedentary group $(P<0.01,+165.4 \%,+22.22 \mathrm{~W}, 95 \% \mathrm{CI}[13.21,31.23])$. There was also a significant difference between the recreational and sedentary group $(P<0.01,+86.3 \%,+11.59 \mathrm{~W}$, $95 \%$ CI $[2.58,20.59])$. The peak speed of the elite group was significantly higher than the recreational $(P<0.05,+18.1 \%)$ and the sedentary groups $(P<0.01,+45.1 \%)$ and the recreational group was significantly higher than the sedentary $(P<0.05,+28.7 \%)$. The elite group covered significantly more distance during the test than the recreational $(P<0.05,+19.1 \%)$ and the sedentary group $(P<0.01,+46.4 \%)$. Once again, significant differences were also evident between the recreational and sedentary groups in the distance covered $(P<0.05,+22.9 \%)$.

239 
242 Table 3: Maximal aerobic and anaerobic test results of elite, recreational SUP. Results expressed as

243 mean \pm SD. $\uparrow=$ significant difference from recreational $*=$ significant difference from sedentary $(P<0.05)$.

\begin{tabular}{|c|c|c|c|}
\hline Parameter & Elite $(\mathrm{n}=15)$ & Recreational $(\mathrm{n}=15)$ & Sedentary $(n=15)$ \\
\hline \multicolumn{4}{|l|}{ Aerobic Performance } \\
\hline $\mathrm{VO}_{2 \max }(\mathrm{L} / \mathrm{min})$ & $3.39 \pm 0.63 \div *$ & $2.44 \pm 0.77^{*}$ & $1.83 \pm 0.57$ \\
\hline $\mathrm{VO}_{2 \max }(\mathrm{ml} / \mathrm{kg} / \mathrm{min})$ & $43.73=5.87 \div *$ & $31.90=7.68^{*}$ & $20.35=3.69$ \\
\hline Respiratory exchange ratio & $1.13 \pm 0.05$ & $1.16=0.11$ & $1.18 \pm 0.07$ \\
\hline $\mathrm{HR}_{\text {peak }}(\mathrm{bpm})$ & $186.60=15.00$ & $187.6 \pm 13.71$ & $173.93=17.21$ \\
\hline Peak lactate $(\mathrm{mmol} / \mathrm{L})$ & $13.70 \pm 3.59$ & $12.43 \pm 3.56$ & - \\
\hline Aerobic power (W) & $30.50=5.98 \div *$ & $21.23 \pm 7.86^{*}$ & $10.56=3.21$ \\
\hline Peak stroke rate (strokes/min) & $69.60=10.59 \div *$ & $55.47 \pm 7.99 *$ & $42.27 \pm 9.02$ \\
\hline Average stroke length (m) & $2.19=0.28$ & $2.24=0.27$ & $2.34 \pm 0.48$ \\
\hline Distance covered (m) & $747.59 \pm 128.66 \div *$ & $503.51=159.97^{*}$ & $368.90 \pm 68.42$ \\
\hline Peak speed $(\mathrm{m} / \mathrm{s})$ & $2.18 \pm 0.16 \div *$ & $1.93 \pm 0.24 *$ & $1.50=0.15$ \\
\hline \multicolumn{4}{|l|}{ Anaerobic Performance } \\
\hline Anaerobic power (W) & $35.67 \pm 11.08 \div *$ & $25.04=11.69^{*}$ & $13.44=7.05$ \\
\hline Relative anaerobic power (W/kg) & $0.46 \pm 0.12 \div *$ & $0.32 \pm 0.13^{*}$ & $0.15 \pm 0.06$ \\
\hline Peak speed $(\mathrm{m} / \mathrm{s})$ & $2.35 \pm 0.32 \div *$ & $1.99 \pm 0.40^{*}$ & $1.62 \pm 0.31$ \\
\hline Distance covered (m) & $20.60 \pm 3.08 \div *$ & $17.29 \pm 3.60^{*}$ & $14.07 \pm 2.88$ \\
\hline
\end{tabular}

244

245 Figure 1 shows the elite group had significantly smaller 100\% squares than the sedentary group

246 in all but the EOML condition and significantly smaller than the recreational group in all but the

247 EO and EOML condition. There were no significant differences between the recreational and

248 sedentary groups with respect to the 100\% square. Overall the EO condition displayed the best

249 postural control as indicated by the lowest velocity of sway and smallest $100 \%$ square of the

250 static tests for all groups. Under the dynamic conditions the EOAP demonstrated the lowest

251 velocity of sway for all groups and the EOAP had the smallest $100 \%$ square amongst the elite

252 and sedentary group while it was smallest in the EOML condition for the recreational group. 


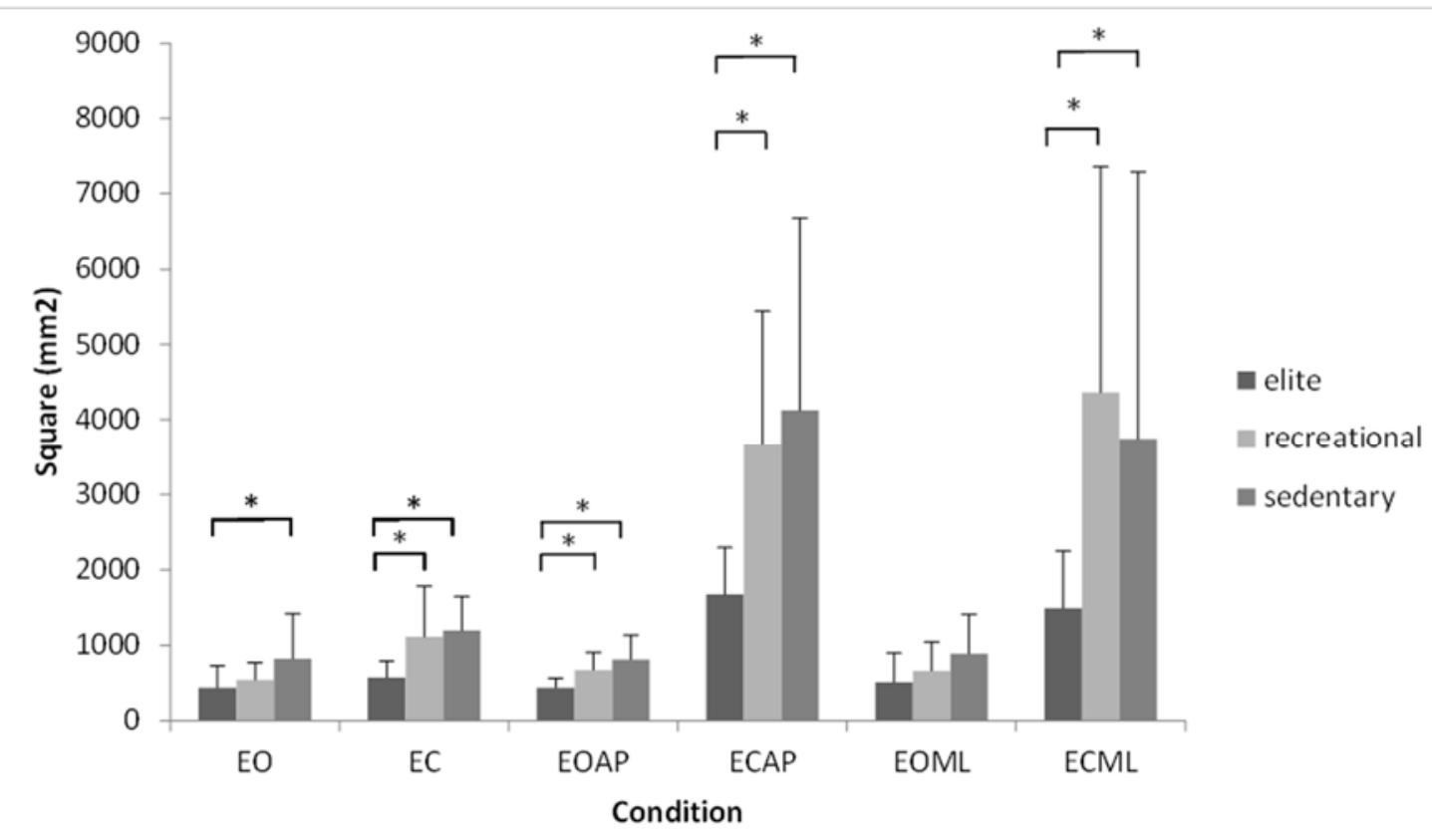

Figure 1: Balance results of participants. Results expressed as mean $\pm \mathrm{SD}$. Where $*=P<0.05 ; \mathrm{EO}=$ eyes open, $\mathrm{EC}=$ eyes closed, AP $=$ Anterior Posterior Instability, ML = Medial Lateral Instability.

258 Figure 2 shows that elite group had significantly lower velocity of sway compared to the

259 recreational group in all conditions, and significantly lower velocity than the sedentary group in

260 both dynamic tests with eyes closed (ECAP, ECML). There were no significant differences

261 between the recreational and sedentary groups with respect to velocity. The highest velocities

262 were recorded in the ECML condition for all groups and the greatest $100 \%$ square was in the

263 ECAP condition for the elite group and ECML for the recreational and sedentary group. There

264 was a significant increase $(P<0.05)$ in velocity and $100 \%$ square for each condition when the

265 subject's eyes were closed as opposed to when they had visual feedback to rely on. 


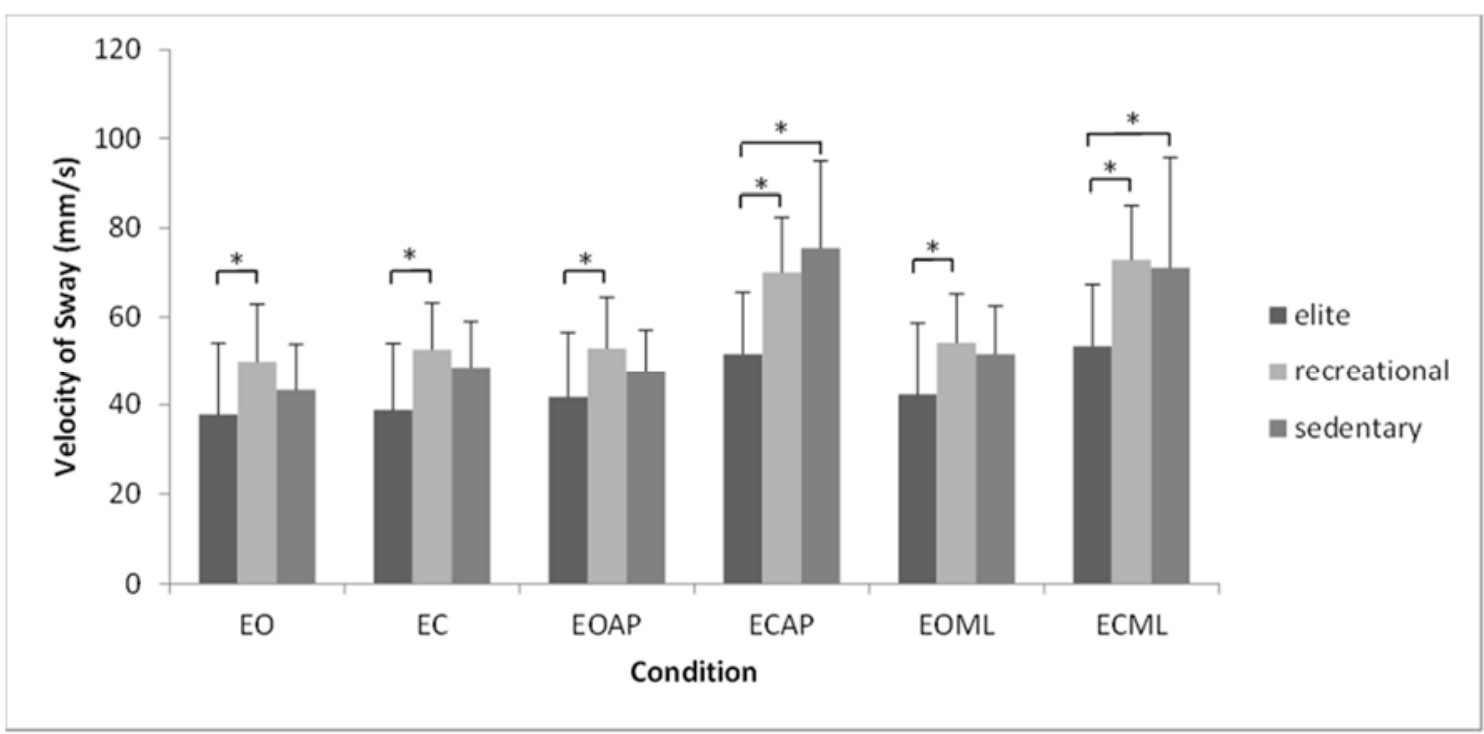

267

268

269

270

271

272

273

274

275

276

277

278

279

280

281

282

283

Figure 2: Balance results EO = eyes open, $\mathrm{EC}=$ eyes closed, $\mathrm{AP}=$ Anterior Posterior Instability, $\mathrm{ML}=$ Medial Lateral Instability. Results are expressed as mean \pm SD. * = Significant diference $(P<0.05)$.

Results for the isometric tests (Figure 3) show many significant differences between the three groups. The elite group had significantly $\left(P<0.05, \eta^{2}=0.71\right)$ longer hold times in the prone bridge than both the recreational $(+53.1 \%,+87.83 \mathrm{sec}, 95 \%$ CI $[44.01,131.65])$ and sedentary group $(+263.4 \%,+183.67 \mathrm{sec}, 95 \%$ CI $[139.85,227.49])$. The recreational group also displayed significantly $(P<0.05)$ longer hold times than the sedentary group $(+137.5 \%,+95.83 \mathrm{sec}, 95 \% \mathrm{CI}$ $[52.01,139.65])$. The right sided bridge was significantly greater $\left(P<0.05, \eta^{2}=0.59\right)$ in the elite group than the recreational $(+58.3 \%,+39.73 \mathrm{sec}, 95 \%$ CI $[16.97,62.48])$ and sedentary groups $(+212.2 \%,+73.36 \mathrm{sec}, 95 \%$ CI $[50.60,96.12])$. The recreational group showed a significantly longer right sided bridge than the sedentary group $(+97.3 \%,+33.63 \mathrm{sec}, 95 \%$ CI $[10.88,56.39])$. The left side bridge was significantly $\left(P<0.05, \eta^{2}=0.61\right)$ greater in the elite than the recreational $(+46.4 \%,+31.62 \mathrm{sec}, 95 \%$ CI $[11.20,52.03])$ and the sedentary $(+207.2 \%,+67.28 \mathrm{sec}, 95 \% \mathrm{CI}$ $[46.87,87.70])$ while the recreational was significantly $(P<0.05)$ greater than the sedentary $(+109.8 \%,+35.67 \mathrm{sec}, 95 \% \mathrm{CI}[15.26,56.08])$. 
285 The elite group demonstrated a non-significant difference in the Biering Sorensen test with the recreational group $(+17.0 \%)$ however a significantly higher $\left(P<0.05, \eta^{2}=0.45\right)$ result in this test when compared to the sedentary group $(+109.3 \%,+77.68 \mathrm{sec}, 95 \%$ CI $[44.45,110.91])$. The difference between the recreational group and the sedentary group was also significant $(P<0.05)$, $+78.9 \%,+56.08 \mathrm{sec}, 95 \%$ CI $[22.85,89.31])$. There were no significant differences between either group (recreational and sedentary) with regards to right and left bridging.

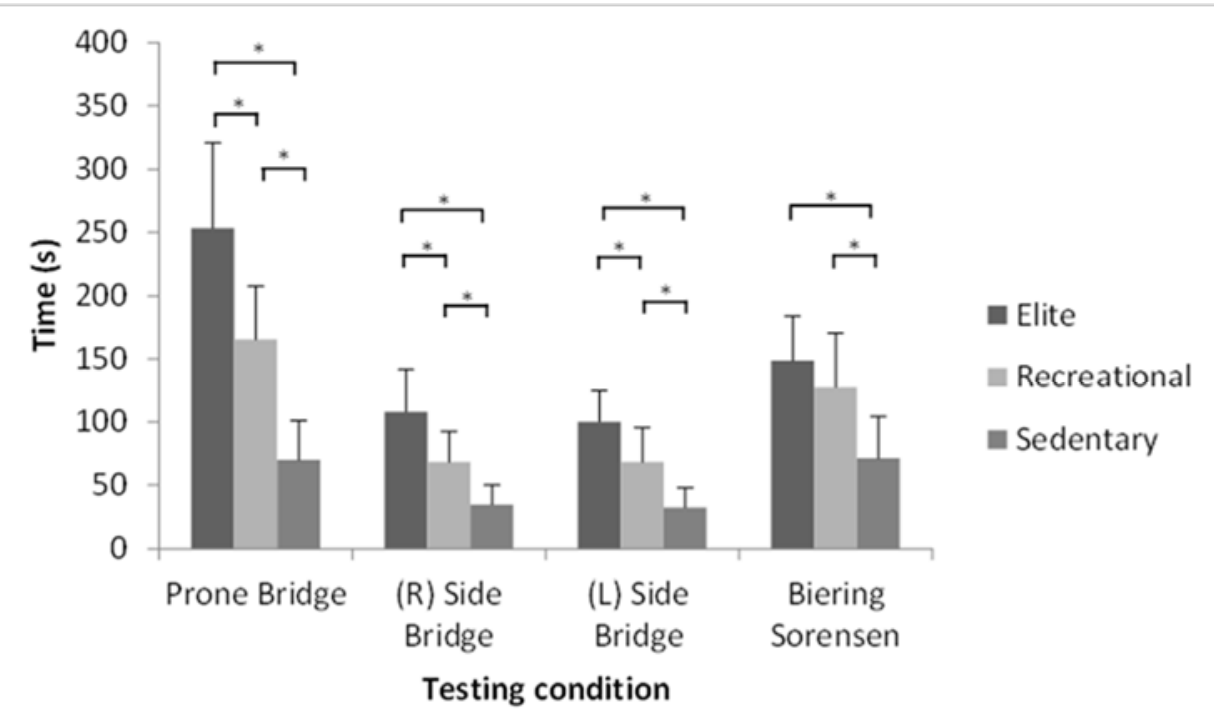

Figure 3: Results of isometric endurance tests. ${ }^{*}=$ significant difference $(P<0.05)$.

\section{Discussion}

296 This was the first study to examine the physiological and musculoskeletal profiles of elite and

297 recreational SUP participants as compared to a sedentary population. The lean body composition

298 finding is similar to Ackland's study on the morphological characteristics of the canoe and kayak

299 athletes attending the 2000 Olympic Games in Sydney (Ackland, Ong, Kerr, \& Ridge, 2003).

300 The elite SUP participants also displayed lower cholesterol, LDL and higher HDL when compared to the recreational and sedentary groups. The elite SUP group demonstrated lipid 
302 profiles within the recommended guidelines set by the Australian Heart Foundation; total

303 cholesterol $<5.5 \mathrm{mmol} / \mathrm{L}, \mathrm{HDL}>1.0 \mathrm{mmol} / \mathrm{L}, \mathrm{LDL}<2.0 \mathrm{~mol} / \mathrm{L}$ and triglycerides $<1.5 \mathrm{mmol} / \mathrm{L}$

304 (Tonkin et al., 2005). The low BMI, high HDL and low LDL and body fat percentage of the elite

305 groups are possibly associated with the training effect of SUP, beckoning further investigation of

306 the actual health benefits of SUP on cardiovascular risk.

307

308 The elite participants profiled in this study displayed comparable levels of maximal aerobic

309 power as seen in other water sports which are upper limb dominant. Previous research has

310 reported surfer's maximal aerobic fitness ranging from $37.8 \mathrm{ml} / \mathrm{kg} / \mathrm{min}$ to $54.2 \mathrm{ml} / \mathrm{kg} / \mathrm{min}$

311 (Loveless \& Minahan, 2010a; Meir, Lowdon, \& Davie, 1991), canoeists from $44.2 \mathrm{ml} / \mathrm{kg} / \mathrm{min}$ to

$31251.9 \mathrm{ml} / \mathrm{kg} / \mathrm{min}$ (Bunc \& Heller, 1991; Hahn, Pang, Tumilty, \& Telford, 1988) and dragon boat

313 racers from $42.3 \mathrm{ml} / \mathrm{kg} / \mathrm{min}$ to $50.2 \mathrm{ml} / \mathrm{kg} / \mathrm{min}$. It should be noted this group included males and

314 females. If adjusted for only the males group the average of $46.84 \mathrm{ml} / \mathrm{kg} / \mathrm{min}$ is comparable to the

315 numbers reported previously.

317 Caution should be used when comparing an upper limb dominant sport with full body water based sports such as rowing and swimming due to the larger muscle mass utilised. It has previously been reported that decreases of $39.36 \%$ in $\mathrm{VO}_{2}$ max when being tested on a treadmill versus being tested on a swim bench (Lowdon, Bedi, \& Horvath, 1989). If a factor of this decrease is added to the figures reported, measures of $65.28 \mathrm{ml} / \mathrm{kg} / \mathrm{min}$ are achieved, which is comparable to other elite athletes of full body water based sports such as rowing (62.88 $\mathrm{ml} / \mathrm{kg} / \mathrm{min})$ (Jurimae, Meaetsu, \& Jurimae, 2000 ) and swimming with $58.4 \mathrm{ml} / \mathrm{kg} / \mathrm{min}$

324 (Roels et al., 2005). Also, to our knowledge, no studies have compared the power output of these 325 various upper limb dominant sports. 
327 The necessity to use caution when comparing aerobic power amongst SUP to other sports is

328 indicated by the results from the sedentary group. In this study, average aerobic power outputs of

$32921.85 \mathrm{ml} / \mathrm{kg} / \mathrm{min}$ from the sedentary males and $17.37 \mathrm{ml} / \mathrm{kg} / \mathrm{min}$ from the females are much

330 lower than previously reported references. Age stratified measures of $35.6, s=7.7 \mathrm{ml} / \mathrm{kg} / \mathrm{min}$

331 have been reported from sedentary males and 27.2, $s=5.0 \mathrm{ml} / \mathrm{kg} / \mathrm{min}$ from sedentary females

332 when utilising cycle ergometers to assess maximal aerobic power (Herdy \& Uhlendorf, 2011).

334 There was a difference in aerobic power outputs reported previously utilising ergometers such as

335 swim bench and rowing ergometers to these SUP results (Farley, Harris, \& Kilding, 2012;

336 Loveless \& Minahan, 2010a). Aerobic power outputs amongst surfers using a swim bench have

337 reached 199W (Loveless \& Minahan, 2010a) and 118W to 158W using modified kayak

338 ergometers (Farley, et al., 2012; Mendez-Villaneuva \& Bishop, 2005). Other water sports have

339 also exhibited large aerobic power outputs including 239W from kayakers (Billat, 1996) 371W

340 from rowers (Jurimae, et al., 2000 ) and 195W from dragon boat racers (Ho, Smith, Chapman,

341 Sinclair, \& Funato, 2012). It is assumed that due to the extensive amount of muscle mass used

342 for stabilization, a small percentage of muscle force may actually contribute toward propulsion

343 of the SUP across the water.

345 Although there was a greater average stroke length of the sedentary group when compared to the 346 recreational $(+4.46 \%)$ and the elite group $(+6.85 \%)$ in the aerobic test, this does not necessarily

347 reflect a better stroke. It can be seen that the stroke rate achieved by the elite group is

348 significantly higher than the recreational group (+25.5\%) and sedentary group $(+64.7 \%)$ and a

349 shorter more powerful stroke is more beneficial to overall performance as indicated by a much

350 greater power output amongst the elites than the recreational group $(+43.7 \%)$ and the sedentary

351 group (+188.8\%). This higher stroke rate with a shorter stroke distance is related to greater 
352 power output, and therefore an increased speed across the water. The inversely proportional

353 relationship found between stroke length and rate is also found in swimming, rowing and

354 outrigging and both of these variables are found to be directly proportional to performance

355 (Sealey, Ness, \& Leicht, 2011).

356

357 The anaerobic power outputs measured in this study are below those recorded in other water

358 based activities including surfing (205W - 348W,(Loveless \& Minahan, 2010b)), swimming

359 (304W, (Hawley \& Williams, 1991)), surf lifesaving (326W (Morton \& Gaston, 1997)) and

360 kayaking (223W, (Fry \& Morton, 1991)). The low numbers could be due to the high amount of

361 muscle activity being used for stabilization on a dynamic surface and consequently minimal

362 muscle activity being used for the overall propulsion. Given our findings, particularly the high

363 levels of maximal aerobic and anaerobic capacity amongst its participants, SUP may be useful

364 for cross-training or athletes wishing to avoid impact after minor injury whilst still developing or

365 maintaining aerobic and anaerobic fitness.

366

367 The potential health benefits of SUP should also be considered. Both elite groups and

368 recreational groups had good to very high maximal oxygen consumptions and favourable lipid

369 profiles. For example, over $83 \%$ of SUP participants (elite and recreational combined) had total

370 cholesterol levels at target $(<5.5 \mathrm{mmol} / \mathrm{L})$ and $93 \%$ had HDL levels at target $(>1.0 \mathrm{mmol} / \mathrm{L})$.

371 However participant's diet and activity levels were not assessed and these parameters would

372 have significant influence on lipid profiles. These lipid profiles combined with favourable BMI

373 and elevated aerobic fitness would afford SUP participants with reduced cardiovascular risk,

374 thereby also providing improved health associated with participation.

375 
376 The elite group displaying a greatest $100 \%$ square in the ECAP condition is most likely due to

377 the lack of exposure to the AP direction and the familiarity ML instability encountered when

378 standing on a SUP. Due to the length of a board, the greatest postural challenge is in the medial

379 lateral direction, possibly explaining why the sedentary and recreational group had the greatest

$380100 \%$ square in the medial - lateral condition. Due to exposure to this condition, their postural

381 control may be increased in this direction amongst the elite.

382

383 It can be seen in this study that expertise decreases both the velocity of sway and area indicated

384 by the $100 \%$ square during postural challenges amongst SUP athletes. This increased dynamic

385 postural control could be due to specific adaptation due to the sport or alternatively, as Chapman

386 discussed, possible due to a gravitation toward, and subsequent success in balance related

387 activities from those who have a genetic predisposition toward superior postural control

388 (Chapman, Needham, Allison, Lay, \& Edwards, 2008). It could also be that this way of

389 measuring dynamic balance is not specific for this sport and therefore not a true reflection of the 390 postural control of SUP participants.

391

392 It is proposed that instability training stresses the neuromuscular system more than traditional

393 training (Anderson \& Behm, 2005) and instability training has been shown to increase knee

394 flexor and extensor strength and also diminish muscle imbalances between dominant and non-

395 dominant sides (Heitkamp, Horstmann, Mayer, Weller, \& Dickhuth, 2001). Kidgell

396 demonstrated that six weeks of training on a mini-tramp was as effective as a dura disc for

397 people who have sustained lateral ankle sprains (Kidgell, Horvath, Jackson, \& Seymour, 2007).

398 Whether SUP would have a similar effect on muscle strength, balance and rehabilitation due to it

399 having a similar unstable surface, is currently unclear.

400 
401 Past studies regarding endurance of the trunk musculature have been centred on back pain with

402 researchers claiming that inadequate trunk endurance is a risk factor in the development and

403 chronicity of low back pain (Arab, Salavati, Ebrahimi, \& Ebrahim Mousavi, 2007; Biering-

404 Sorensen, 1984; O'Sullivan, Mitchell, Bulich, Waller, \& Holte, 2006). The prone bridge has

405 been used to assess trunk flexor endurance previously, and decreased endurance times as low as

$40628.3, s=26.8$ seconds have been found amongst symptomatic back pain sufferers (Schellenberg,

407 Lang, Chan, \& Burnham, 2007). Ranges of between 92 and 124 seconds have been reported

408 from fit, healthy firefighters,(McGill, et al., 2010) well below the numbers reported amongst

409 these SUP athletes. The endurance hold times of the lateral abdominal wall measured with the

410 side bridges amongst SUP athletes were similar to an athletic population of $87.5, s=36.4$

411 seconds on the right and 92, $s=45.8$ seconds on the left (Evans, et al., 2007).

413 The extensor endurance amongst the both SUP groups were similiar to previously published

414 papers including McGill's study which showed an average men's endurance time of 146s,

415 women's 189s amongst young, healthy individuals (McGill, Childs, \& Leiebenson, 1999),

416 higher than Adedoyin's of 119, $s=47 \mathrm{~s}$ for men and 106, $s=44 \mathrm{~s}$ for women (Adedoyin, Mbada,

417 Farotimi, Johnson, \& Emechete, 2011), and much higher than Alaranta, who demonstrated 97s

418 men and 87s women (Alaranta, 1994). Results obtained in this study are also greater than a

419 group of athletes who had back pain with an average hold times of 107.5s (Stewart, Latimer, \&

420 Jamieson, 2003).

422 It has been demonstrated previously that the endurance of the core muscles can be improved

423 with core training (Aggarwal, Kumar, \& Kumar, 2010). Significant improvements in hold times

424 of all the above tests were made with six weeks of core training including multidirectional

425 movements and instability with the use of a swiss ball. As the core muscles seem to be activated 
426 by SUP and these athletes demonstrate adequate endurance hold times, perhaps SUP could be

427 used to increase endurance of the core muscles and therefore be used as a prophylactic treatment

428 for back pain.

429

430 The minimal difference amongst the SUP participants in regards to left and right bridge times is

431 most probably due to the paddling motion being performed bilaterally, typically alternating on a

432 regular 10-14 stroke basis. Muscle imbalances are rife amongst competitive canoeists and

433 outriggers who paddle on the one side (Stambolieva, Diafas, Bachev, Christova, \& Gatev, 2011)

434 and it is thought that muscle imbalance could be related to injury occurrence (Franettovich,

435 Hides, Mendis, \& Littleworth, 2011). The slightly higher, difference right sided bridge score is

436 most likely due to the prevalence of right hand dominance.

437

438 The aim of this investigation was to profile SUP in regards to physiological and musculoskeletal

439 parameters. In summary, there appears to be a high level of aerobic and anaerobic fitness,

440 dynamic postural control and a high level of trunk muscle endurance amongst those who

441 participate in SUP. It would appear as though greater levels of fitness, strength and balance are

442 associated with higher participation.

443

444

445

446 
447

448

449

450

451

452

453

454

455

456

457

458

459

460

461

462

463

464

465

466

467

468

469

470

471

472

473

474

475

476

477

478

479

480

481

482

483

484

485

486

487

488

489

490

491

492

493

494

495

496

\section{References}

Ackland, T. R., Ong, K. B., Kerr, D. A., \& Ridge, B. (2003). Morphological characteristics of Olympic spring canoe and kayak paddlers. Journal of Science and Medicine in Sport 6(3), 285-294.

Adedoyin, R. A., Mbada, C. E., Farotimi, A. O., Johnson, O. E., \& Emechete, A. I. (2011). Endurance of low back musculature: Normative data for adults. Journal of back and Musculoskeletal Rehabilitation, 24, 101-109.

Aggarwal, A., Kumar, S., \& Kumar, D. (2010). Effect of Core Stabilization Training on the Lower Back Endurance in Recreationally Active Individuals. Journal of Musculoskeletal Research, 13(4), 167-176.

Alaranta, A. M., M. Elmqvist, L. G, Held, J. Pope, M. Renstrom, P. (1994). Postural Control of Adults with Musculoskeletal Impairment. Critical Reviews in Physical and Rehabilitation Medicine, 6, 337-370.

Anderson, K., \& Behm, D. (2005). The impact of instability resistance training on balance and stability Sports Medicine, 35(1), 43-53.

Arab, A. M., Salavati, M., Ebrahimi, I., \& Ebrahim Mousavi, M. (2007). Sensitivity, specificity and predictive value of the clinical trunk muscle endurance tests in low back pain. Clinical Rehabilitation, 21, 640-647.

Behm, D., G., Leonard, A., M., Young, W., B., Bonsey, W., A, C. , \& Mackinnon, S., N. (2005). Trunk muscle electromyographic activity with unstable and unilateral exercises. Journal of Strength and Conditioning Research, 19, 106-119.

Biering-Sorensen, F. (1984). Physical measurements as risk indicators for low back trouble over a one year period. Spine, 9, 106-119.

Billat, V., Faina, M., Sardella, F., Marini, C., Fanton, F., Lupo, S., Faccini, P., De Angelis, M., Koralsztein, J.P., Dalmonte, A. (1996). A comparison of time to exhaustion at VO2 max in elite cyclists, kayak paddlers, swimmers and runners. Ergonomics, 39(2).

Bunc, V., \& Heller, J. (1991). Ventilatory threshold and work efficiency on a bicycle and paddling ergometer in top canoeists. Journal of Sports Medicine and Physical Fitness, 31(3), 376-379.

Chapman, D. W., Needham, K. J., Allison, G. T., Lay, B., \& Edwards, D. J. (2008). Effects of experience in a dynamic environment on postural control. British Journal of Sports Medicine, 42(1), 16-21. doi: 10.1136/bjsm.2006.033688

Danneels, L. A., Vanderstraeten, G. G., \& Cambier, D. C. (2001). Effects of three different training modalities on the cross-sectional area of the lumbar multifidus muscle in patients with chronic low back pain. British Journal of Sports Medicine, 35, 186-191.

Evans, K., Refshauge, K. M., \& Adams, R. (2007). Trunk muscle endurance tests: reliability, and gender differences in athletes. [Evaluation Studies]. Journal of Science and Medicine in Sport / Sports Medicine Australia, 10(6), 447-455. doi: 10.1016/j.jsams.2006.09.003

Farley, O., Harris, N. K., \& Kilding, A. E. (2012). Anaerobic and aerobic fitness profiling of competitive surfers. Journal of Strength and Conditioning Research / National Strength \& Conditioning Association, 26(8), 2243-2248. doi: 10.1519/JSC.0b013e31823a3c81

Franettovich, M., Hides, J., Mendis, M. D., \& Littleworth, H. (2011). Muscle imbalance among elite athletes. British Journal of Sports Medicine, 45(4), 348-349. doi: 10.1136/bjsm.2011.084038.109

Fry, F. R., \& Morton, A. R. (1991). Physiological and kinarthropometric attributes of elite flatwater kayakists. Medicine and Science in Sports and Exercise, 23(11), 1297-1301.

Hahn, A. G., Pang, P. M., Tumilty, D. M., \& Telford, R. D. (1988). General and specific aerobic power of elite marathon kayakers and canoeists. EXCEL, 5(2), 14-19.

Hammer, S. (2011). Catch the wave of stand up paddling. The Providence Journal, Sep 5, 3. 
497

498

499

500

501

502

503

504

505

506

507

508

509

510

511

512

513

514

515

516

517

518

519

520

521

522

523

524

525

526

527

528

529

530

531

532

533

534

535

536

537

538

539

540

541

542

543

544

545

546
Hawley, J. A., \& Williams, M. M. (1991). Relationship between upper body anaerobic power and freestyle swimming performance. International Journal of Sports Medicine, 12(1), $1-5$.

Heitkamp, H. C., Horstmann, T., Mayer, F., Weller, J., \& Dickhuth, H. H. (2001). Gain in strength and muscular balance after balance training. International Journal of Sports Medicine, 22(4), 285-290. doi: 10.1055/s-2001-13819

Herdy, A. H., \& Uhlendorf, D. (2011). Reference Values for Cardiopulmonary Exercise Testing for Sedentary and Active Men and Women. Arquivos Brasileiros de Cardiologia, 96(1), 54-59.

Ho, S. R., Smith, R. M., Chapman, P. G., Sinclair, P. J., \& Funato, K. (2012). Physiological and Physical characteristics of elite dragon boat paddlers. Journal of Strength and Conditioning Research, Publish Ahead of Print.

Jurimae, J., Meaetsu, J., \& Jurimae, T. (2000 ). Prediction of rowing performance on single sculls from metabolic and antropometric variables. Journal of Human Movement Studies, 38, 123-136.

Kidgell, D., J, Horvath, D., M, Jackson, B., M, \& Seymour, P., J. (2007). Effect of six weeks of dura disc and mini trampoline balance training on postural sway in athletes with functional ankle instability. Journal of Strength and Conditioning Research, 21(2), 466469.

Loveless, D., \& Minahan, C. (2010a). Peak aerobic power and paddling efficiency in recreational and competitive junior male surfers. European Journal of Sports Science, 10(6), 407-415. doi: 10.1080/17461391003770483

Loveless, D., \& Minahan, C. (2010b). Two reliable protocols for assessing maximal-paddling performance in surfboard riders. Journal of Sports Science, 28(7), 797-803. doi: $10.1080 / 02640411003770220$

Lowdon, B. J., Bedi, J. F., \& Horvath, S. M. (1989). Specificity of aerobic fitness testing of surfers. Australian Journal of Science and Medicine in Sport, 21, 7-10.

Lukaski, H. C., Bolonchuk, W. W., Hall, C. B., \& Siders, W. A. (1986). Validation of tetrapolar bioelectrical impedance method to assess human body composition. Journal of Applied Physiology, 60(4), 1327-1332.

McGill, S., M., Belore, M., Crosby, I., \& Russell, C. (2010). Clinical tools to quantify torso flexion endurance: Normative data from student and firefighter populations. Occupational Ergonomics, 9, 55-61. doi: 10.3233/oer-2010-0181

McGill, S., M., Childs, A., \& Leiebenson, C. (1999). Endurance times for stabilisation exercises: Clincal targets for testing and training from a normal database. Archive of Physical Medicine and Rehabilitation(80), 941-944.

McGill, S., M., Grenier, S., Kavcic, N., \& Cholewicki, J. (2003). Coordination of muscle activity to assure stability of the lumbar spine. Journal of Electromyography and Kinesiology, 13(4), 353-359. doi: 10.1016/s1050-6411(03)00043-9

Meir, R., Lowdon, B. J., \& Davie, A., J. (1991). Heart rates and estimated energy expenditure during recreational surfing. Journal of Science and Medicine in Sport 23, 70-74.

Mendez-Villaneuva, A., \& Bishop, D. (2005). Physiological Aspects of Surfboard Riding Performance. Journal of Sports Medicine, 35(1), 55-70.

Molokai2Oahu. Retrieved 9th December, 2012 from www.molokai2oahu.com

Morton, D. P., \& Gaston, P. B. (1997). Effect of high intensity board training on upper body anaerobic capacity and short-lasting exercise performance. Australian Journal of Science and Medicine in Sport, 29, 17-21.

O'Sullivan, P. B., Mitchell, T., Bulich, P., Waller, R., \& Holte, J. (2006). The relationship beween posture and back muscle endurance in industrial workers with flexion-related low back pain. Manual Therapy, 11(4), 264-271. doi: 10.1016/j.math.2005.04.004 
547 Palliard, T., Margnes, E., Portet, M., \& Breucq, A. (2011). Postural ability reflects the athletic

548

549

550

551

552

553

554

555

556

557

558

559

560

561

562

563

564

565

566

567

568

569

570

571

572

573

574

575

576

577

578

579

580

581

582

583 skill level of surfers. European Journal of Applied Physiology, 111(8), 1619-1623. doi: 10.1007/s00421-010-1782-2

Roels, B., Schmitt, L., Libicz, S., Bentley, D., Richalet, J. P., \& Millet, G. (2005). Specificity of VO2 max and the ventilatory threshold in free swimming and cycle ergometry: comparison between triathletes and swimmers. British Journal of Sports Medicine, 39, 965-968.

Schellenberg, K. L., Lang, J. M., Chan, K. M., \& Burnham, R. S. (2007). A clinical tool for office assessment of lumbar spine stabilization endurance: prone and supine bridge maneuvers. American Journal of Physical Medicine \& Rehabilitation, 86(5), 380-386.

Sealey, R. M., Ness, K. F., \& Leicht, A. S. (2011). Effect of self-selected and induced slow and fast paddling on stroke kinematics during $1000 \mathrm{~m}$ outrigger canoeing ergometry. Journal of Sports Science and Medicine 10, 52-58.

Stambolieva, K., Diafas, V., Bachev, V., Christova, L., \& Gatev, P. (2011). Postural stability of canoeing and kayaking young male athletes during quiet stance. European Journal of Applied Physiology. doi: 10.1007/s00421-011-2151-5

Stewart, M., Latimer, J., \& Jamieson, M. (2003). Back Extensor Endurance Test Scores in Coal Miners in Australia. Journal of Occupational Rehabilitation, 13(2), 79-89.

Tonkin, A., Cooper, C., Robinson, M., Clune, E., Barter, P., Best, J., . . New, Z. (2005). National Heart Foundation of Australia and the Cardiac Society of Australia and New Zealand: position statement on lipid management--2005. Heart, Lung \& Circulation, 14(4), 275-291.

Vera-Garcia, F., J., Grenier, S., G., \& McGill, S., M. (2000). Abdominal muscle response during curl ups on both stable and labile surfaces. Physical Therapy, 80, 564-569.

Walker, C., Nichols, A., \& Forman, T. (2010). A Survey of Injuries and Medical Conditions Affecting Stand-Up Paddle Surfboarding Participants. Clinical Journal of Sports Medicine, 20(2), 144. 
585

586

587

588

589 